sea-bed and along the shores. When the International Geographical Congress meets in London this summer, Dr. Kidson will lead a number of international specialists in an investigation of the coasts of south and south-west England.

\section{Research Centre for the World Health Organization}

The question of a research centre for the World Health Organization was again raised in a debate in the House of Commons on May 15 by Mr. W. Hamilton, who referred to a report of Scientific Advisers on the Special Development of International Health and Biochemic Research, dated December 1963, and to debates in the Organization in January and March 1964 - reports of which are not as yet published. Replying for the Government on the debate, tho Under-Secretary of State for Scotland, Mr. J. A. Stodart, said that the Executive Board of the World Health Organization first considered the proposal for a World Health Research Centre in January 1964, and the proposal had been prepared after an extensive canvass of expert opinion. Nevertheless, the Advisory Council for Scientific Policy advised the Government that establishment of an international centre for biological research on the lines proposed would be unjustified at this time and could adversely affect the work of the scientists concerned by depriving them of their existing contacts at national centres with established laboratories and other workers in associated fields. In accordance with this advice, the United Kingdom delegation spoke against the proposal at a subsequent meeting of the World Health Organization Assembly on March 5, but Mr. Stodart pointed out that opposition was not in any way intended to reject the whole proposal out of hand. $\mathrm{He}$ assured the House that Britain would give the Director-General all the assistance she could in the further enquiries he now had to make, but it was premature to speak of particular sites for the centre. That decision was one to be made by the Organization itself and Britain was only one of its 118 members. He thought that the timing of any offer of a location was most important, but while any such offer should be forcefully made it was premature until a decision had been taken to establish the centre.

\section{International Institute for Basic Research into the Life Sciences}

THE Belgian Government has made a gift of 13,000 dollars to Unesco to study the possibility and desirability of setting up an institute for basic research into the life sciences. The possibility of also creating an international foundation to encourage exchange of scientific workers and co-operation between European centres working on molecular biology will also be studied. Specifically, the Director-General of Unesco has been authorized to set up an expert committee to advise him on the planning of such a study and submit racommendations for future action. The study should be completed and ready for consideration by Member States prior to the thirteenth session of Unesco's general conference in October. The expert committee, before reaching any conclusions, will consult the European Molecular Biology Organization and the International Life Sciences Institute.

\section{The Problems of Higher Education in France}

IN November 1963 the French Minister of Education, M. Christian Fouchet, set up a Commission to devise reforms for higher education. The first task the Commission has set itself is to define the business of higher education and the means of access to this education. It sees its mission as four-fold: the general and technical training of the nation's management and key personnel, and their continued further training; the training of research workers; the training of teachers; and the dissemination of "high literary, artistic, scientific and technical culture". In Oetober 1964 the number of students of the present university year will be greatly exceeded, although these already amount to 300,000 . It is probable that the reality will exceed the forecasts of the Fourth Plan, which estimated the number of students in 1970 at more than half a million. If one considers probable an increase of about 80,000 in the number of students at the beginning of the 1964 academic year, France is in a different position from that of other countries of Westerm Europe, such as Britain, Germany or Italy. In numbers, French higher education will thus tend to compare with American education, where it is considered normal for 25 per cent of the young people to continue their studies beyond the age of eighteen. Does this growth in the university population correspond to needs ? In June 1963, M. Fouchet recalled that the number of students still represents only 0.6 per cent of the French population, as against 1.8 per cent in the United States and 1.4 per cent in the U.S.S.R. "The percentage of 1 per cent anticipated for 1970," he said, "is in no way excessive if our country wishes to retain its place in the world." The ways in which the increased numbers of students are to be obtained are described in a memorandum prepared by the French Embassy (Pp. 16. London: Ambassade de France, Service de Presse et d'Information, 1964).

\section{A Democratic Plan for a National Incomes Policy}

Dr. E. JACQUes claims in a pamphlet, entitled National Incomes Policy : a Democratic Plan, that it is possible to devise a scientific and generally acceptable plan for translating unexceptional general principles into effective practice (Pp. 8. London: K-H Services, 162 Buckingham Palace Road, 1964. 2s. net). This would equitably determine what each employed person should receive from the money value of the national product. He maintains that there exist intuitively known norms of fair payment for given levels of work, and that these norms are shared among all employed people independently of the supply and demand situation. These norms have been made manifest by the use of what he terms the "time-span of discretion' for measuring objectively the level of work in any employment role from shop-floor to management. This measure is the maximum time lapse over which a person is required to exercise discretion in his job without that discretion being reviewed. Dr. Jacques emphasizes that it is not job evaluation but objective measurement in the full meaning of measurement, ordinarily associated with the natural sciences, and that the instrument has been applied by himself and others to some 3,000 jobs in the United Kingdom and other countries. With this, under full employment and a buoyant economy, he argues that a national incomes policy is practicable.

\section{Science and the Civil Service}

Tre ninety-seventh report of the Civil Service Commissioners, covering the period January 1-December 31, 1963 , notes an innovation in the traditional form of competition in the exemption from academic papers of candidates holding first-class honours degrees and scoring a high total of marks for the qualifying examination and interview (Pp. $\mathrm{v}+30$. London: H.M.S.O., 1964. 3s. 6d. net). The system of continuous competition was extended during the year and is now used for inspectors of factories in the Ministry of Labour, and most scientific, engineering and technical grades. A new competition to increase the number of statisticians entering the Service was introduced during the year. In 1963 the staff of the Commission moved to new quarters and for the first time for years is now under one roof. The numbers recruited for the scientific officer class were rather lower during 1963, but increased interest shown at university meetings holds some prospect of better results in 1964. About a dozen seientists in North America were recruited to Government departments through the interview boards 